\title{
Acebutolol, atenolol, and propranolol and metabolic responses to acute hypoglycaemia in diabetics
}

\author{
S P DEACON, A KARUNANAYAKE, D BARNETT
}

British Medical fournal, 1977, 2, 1255-1257

\section{Summary}

In a double-blind crossover study the symptomatic and metabolic effects of propranolol, acebutolol, and atenolol were studied during insulin-induced hypoglycaemia in diabetics treated with diet or hypoglycaemic tablets. All the drugs prevented tachycardia, but did not affect the other symptoms of hypoglycaemia. Propranolol delayed the recovery of the blood glucose concentration and impaired the secondary rise in the concentrations of blood lactate and non-esterified fatty acids in diet-treated diabetics. Acebutolol potentiated the hypoglycaemic effect of insulin in tablet-treated diabetics (mean difference of blood glucose concentration $0.7 \mathrm{mmol} / 1$ (12.6 $\mathrm{mg} / 100 \mathrm{ml})$ ) and this difference was maintained during the recovery phase ${ }^{4}$ the blood lactate response was also impaired. Atenolol did not differ perceptibly from placebo in its effects on the metabolic responses to acute hypoglycaemia.

The results may be explained by differences in the known pharmacological actions of these drugs. They support the hypothesis that beta-adrenoreceptor blocking drugs that are highly beta ${ }_{1}$ specific and without membrane-stabilising activity should be safer than the non-selective drugs when used in diabetic patients at risk from hypoglycaemia.

\section{Introduction}

Beta-adrenoreceptor blocking drugs may produce troublesome hypoglycaemic side effects in diabetic patients. ${ }^{1}$ The nonselective drugs such as propranolol may potentiate hypoglycaemia and delay the recovery of blood glucose concentrations. ${ }^{1-3}$ Recent studies have, however, indicated that the cardioselective drugs may not increase the risk of hypoglycaemia. In normal subjects atenolol (Tenormin) does not potentiate hypoglycaemia or delay blood glucose recovery ${ }^{4}$; and acebutolol (Sectral), although potentiating initial hypoglycaemia, does not prevent blood glucose recovery. ${ }^{5}$ The findings with metoprolol (Lopressor) have proved inconclusive, but one report showed that it had no adverse effects on blood glucose concentrations. ${ }^{3}$ These findings suggest that the cardioselective drugs might be safer for use in diabetic patients. ${ }^{6}$ Unfortunately, this hypothesis is based on findings in normal subjects, which are not strictly applicable to diabetics. We therefore performed a study to test the hypothesis by determining the effects of atenolol and acebutolol during insulin-induced hypoglycaemia in otherwise healthy diabetics.

Pilgrim Hospital, Boston, Lincolnshire

S P DEACON, MB, CHB, general practice vocational trainee

St James's Hospital, Leeds

A KARUNANAYAKE, MRCP, medical registrar

D BARNETT, MRCP, consultant physician

\section{Patients and methods}

A double-blind crossover study was performed in 12 diabetics. Six were treated on diet alone and six treated with glibenclamide $5-20 \mathrm{mg}$ daily (one also had metformin). There were 10 men and two women, with a mean age of 46 years (15-56). All subjects were normotensive, with normal resting and exercise electrocardiograms and no evidence of diabetic retinopathy. During the study they adhered to their usual treatment and avoided prolonged exercise.

Patients taking hypoglycaemic tablets underwent three episodes of insulin-induced hypoglycaemia at roughly weekly intervals. For 48 hours before each test they took either (a) acebutolol $200 \mathrm{mg}$ twice a day, (b) atenolol $50 \mathrm{mg}$ twice a day, or (c) placebo twice a day, with a

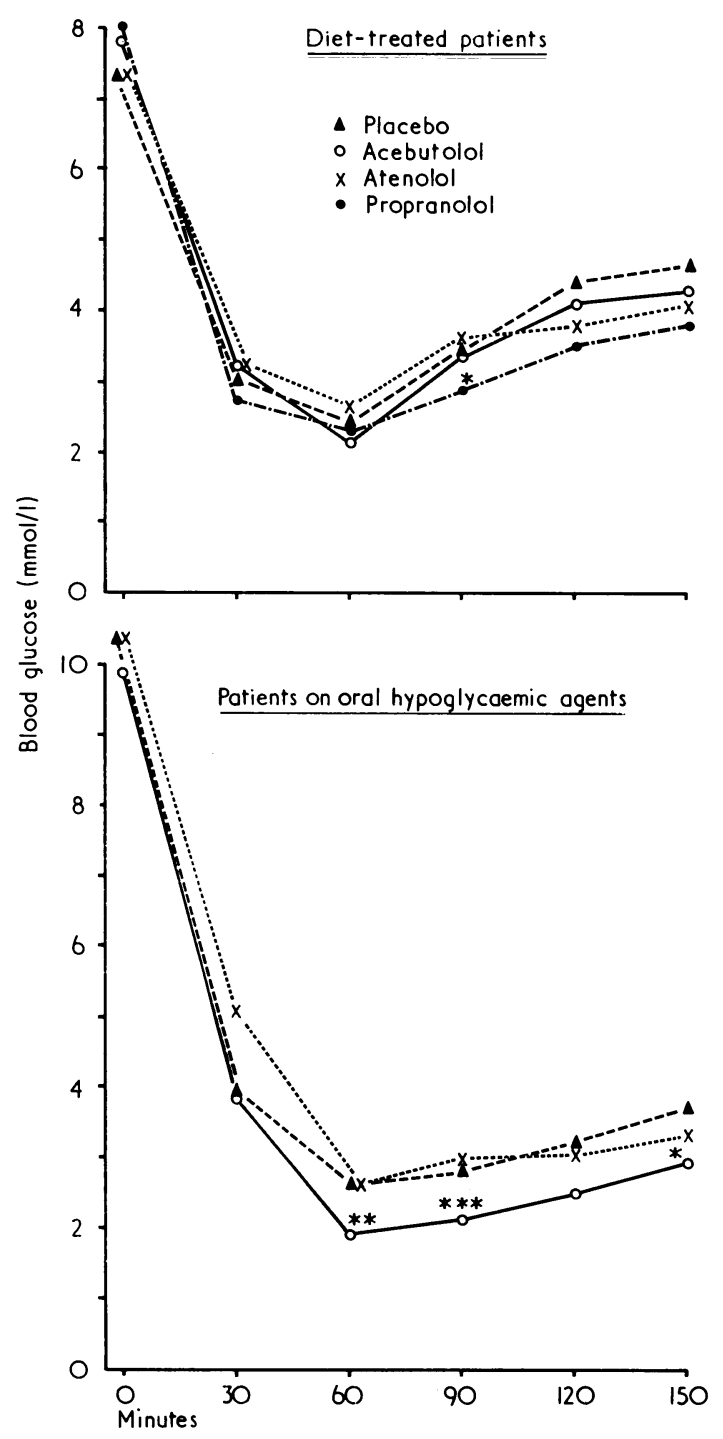

Blood glucose concentrations in six diet-treated diabetics and six taking oral hypoglycaemic agents during insulin-induced hypoglycaemia test.

$* \mathrm{P}<0.05 ; * * \mathrm{P}<0.01 ; * * * \mathrm{P}<0.001-$ for difference from control.

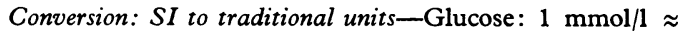
$18 \mathrm{mg} / 100 \mathrm{ml}$. 
TABLE $\mathrm{I}-$ Mean pulse rates per minute $( \pm S E$ of mean $)$

\begin{tabular}{|c|c|c|c|c|c|c|c|}
\hline \multirow{2}{*}{ Drug } & \multicolumn{6}{|c|}{ Time (minutes) } & \multirow{2}{*}{$\begin{array}{l}\text { Increment } \\
\text { after } \\
\text { exercise }\end{array}$} \\
\hline & 0 & 30 & 60 & 90 & 120 & 150 & \\
\hline $\begin{array}{l}\text { Placebo }(n=12) \\
\text { Acebutolol }(n=12) \\
\text { Atenolol }(n=12) \\
\text { Propranolol }(n=6)\end{array}$ & $\begin{array}{l}68 \cdot 9 \pm 2 \cdot 4 \\
63 \cdot 8 \pm 3 \cdot 0 \\
58 \cdot 3 \pm 2 \cdot 9^{* *} \\
57 \cdot 0 \pm 1 \cdot 9^{* * *}\end{array}$ & $\begin{array}{l}71 \cdot 0 \div 2 \cdot 6 \\
64 \cdot 7 \pm 2 \cdot 6^{*} \\
59 \cdot 5: 3 \cdot 0^{* *} \\
54 \cdot 3 \pm 3 \cdot 3^{* * *}\end{array}$ & $\begin{array}{l}74 \cdot 4 \pm 3 \cdot 8 \\
65 \cdot 4 \pm 2 \cdot 6^{*} \\
61 \cdot 0 \pm 3 \cdot 7^{*} \\
49 \cdot 7 \pm 3 \cdot 1^{* * *}\end{array}$ & $\begin{array}{l}72 \cdot 3 \pm 3 \cdot 6 \\
60 \cdot 3 \pm 2 \cdot 9^{* *} \\
56 \cdot 8 \pm 2 \cdot 5^{* * *} \\
50 \cdot 8 \pm 3 \cdot 8^{* * *}\end{array}$ & $\begin{array}{l}67 \cdot 6+2 \cdot 8 \\
59 \cdot 0 \div 2 \cdot 7^{* *} \\
55 \cdot 8+1 \cdot 8^{* * *} \\
51 \cdot 7: 3 \cdot 7^{* * *}\end{array}$ & $\begin{array}{l}68 \cdot 2+3 \cdot 7 \\
61 \cdot 0+3 \cdot 1^{*} \\
56 \cdot 9+2 \cdot 1^{* *} \\
53 \cdot 6 \pm 1^{* * *}\end{array}$ & $\begin{array}{l}33 \cdot 8+3 \cdot 9 \\
21 \cdot 7 \div 4 \cdot 0^{* * *} \\
21 \cdot 5 \div 3 \cdot 9^{* *} \\
20 \cdot 0 \div 6 \cdot 3^{*}\end{array}$ \\
\hline
\end{tabular}

${ }^{*} \mathrm{P}<0.025 ;{ }^{* *} \mathrm{P}<0.0025 ;{ }^{* * *} \mathrm{P}<0.0005$-difference from corresponding control group, paired Student's $t$ test.

TABLE II-Mean blood lactate concentrations in mmolll ( $\pm S E$ of mean)

\begin{tabular}{|c|c|c|c|c|c|c|}
\hline \multirow{2}{*}{ Drug } & \multicolumn{6}{|c|}{ Time (minutes) } \\
\hline & 0 & 30 & 60 & 90 & 120 & 150 \\
\hline \multicolumn{7}{|c|}{ Diet-treated patients $(n=6)$} \\
\hline $\begin{array}{l}\text { Placebo } \\
\text { Accbutolol } \\
\text { Atenolol } \\
\text { Propranolol }\end{array}$ & $\begin{array}{l}0.97 \pm 0.17 \\
0.92 \pm 0.07 \\
0.83 \pm 0.01 \\
0.99: 0.07\end{array}$ & $\begin{array}{l}1 \cdot 11 \pm 0.17 \\
1.28 \pm 1.11 \\
1.13 \pm 0.06 \\
1.36 \pm 0.11\end{array}$ & $\begin{array}{l}1.49 \pm 0.27 \\
1.28 \pm 0.07 \\
1.29 \pm 0.11 \\
1.33 \pm 0.08\end{array}$ & $\begin{array}{l}1.71 \pm 0.36 \\
1.27 \pm 0.13 \\
1.52 \pm 0.26 \\
1.21 \div 0.08\end{array}$ & $\begin{array}{l}1.40 \pm 0.31 \\
1.08 \pm 0.10 \\
1.25 \pm 0.15 \\
1.13 \pm 0.11\end{array}$ & $\begin{array}{l}1.00 \pm 0.21 \\
1.06 \pm 0.13 \\
1.03=0.11 \\
0.95 \pm 0.08\end{array}$ \\
\hline \multicolumn{7}{|c|}{ Patients on oral hypoglycaemic agents $(n=6)$} \\
\hline $\begin{array}{l}\text { Placebo } \\
\text { Acebutolol } \\
\text { Atenolol }\end{array}$ & $\begin{array}{l}1 \cdot 18 \pm 0.13 \\
1 \cdot 14 \pm 0.08 \\
1.51 \pm 0 \cdot 22\end{array}$ & $\begin{array}{l}1.56 \pm 0 \cdot 10 \\
1.47 \pm 0.10 \\
1 \cdot 48 \pm 0.20\end{array}$ & $\begin{array}{l}1 \cdot 76: 0 \cdot 11 \\
1 \cdot 49: 0 \cdot 12 \\
1 \cdot 70: 0 \cdot 21\end{array}$ & $\begin{array}{l}1.970 .16 \\
1.52: 0.11^{*} \\
2.07 \\
0.32\end{array}$ & $\begin{array}{l}1.82 \pm 0.21 \\
1.36 \pm 0.13 * \\
1.87 \pm 0.34\end{array}$ & $\begin{array}{l}1 \cdot 22 \pm 0.13 \\
1.13+0.12 \\
1.73 \pm 0.27\end{array}$ \\
\hline
\end{tabular}

${ }^{*} \mathrm{P}<0.025$ for difference from control.

Conversion: SI to traditional units-Lactate: $1 \mathrm{mmol} / 1 \approx 9 \mathrm{mg} / 100 \mathrm{ml}$

TABLE III-Mean blood NEFA concentrations in $\mu$ mol $/ l( \pm S E$ of mean)

\begin{tabular}{|c|c|c|c|c|c|c|}
\hline \multirow{2}{*}{ Drug } & \multicolumn{6}{|c|}{ Time (minutes) } \\
\hline & 0 & 30 & 60 & 90 & 120 & 150 \\
\hline \multicolumn{7}{|c|}{ Diet-treated patients $(\mathrm{n}=6)$} \\
\hline $\begin{array}{l}\text { Placebo } \\
\text { Acebutolol } \\
\text { Atenolol } \\
\text { Propranolol }\end{array}$ & $\begin{array}{l}665 \pm 70 \\
473 \pm 48^{*} \\
489 \pm 58^{*} \\
478 \pm 68^{*}\end{array}$ & $\begin{array}{l}320 \pm 57 \\
288 \pm 33 \\
279 \pm 46 \\
269 \pm 51\end{array}$ & $\begin{array}{l}362 \pm 78 \\
331 \pm 46 \\
383 \pm 85 \\
243 \pm 17\end{array}$ & $\begin{array}{l}458 \pm 72 \\
325 \pm 25^{*} \\
397 \pm 35 \\
225 \pm 44^{* *}\end{array}$ & $\begin{array}{l}434 \pm 43 \\
350 \pm 29 * \\
371 \pm 50 \\
303 \pm 39^{* *}\end{array}$ & $\begin{array}{l}474 \pm 100 \\
385 \pm 54 \\
456 \pm 55 \\
465 \pm 115\end{array}$ \\
\hline \multicolumn{7}{|c|}{ Patients on oral hypoglycaemic agents $(n=6)$} \\
\hline $\begin{array}{l}\text { Placebo } \\
\text { Acebutolol } \\
\text { Atenolol }\end{array}$ & $\begin{array}{l}612=86 \\
475=62^{*} \\
509 \pm 86\end{array}$ & $\begin{array}{l}272 \pm 44 \\
248 \pm 14 \\
280 \pm 47\end{array}$ & $\begin{array}{l}291 \pm 60 \\
243 \pm 32 \\
309 \pm 63\end{array}$ & $\begin{array}{l}300 \pm 45 \\
278=31 \\
272 \pm 34\end{array}$ & $\begin{array}{l}360 \pm 38 \\
277 \pm 32 \\
316 \pm 51\end{array}$ & $\begin{array}{l}390 \pm 62 \\
418 \pm 72 \\
381 \pm 76\end{array}$ \\
\hline
\end{tabular}

${ }^{*} \mathrm{P}<0.05 ; * * \mathrm{P}<0.01$-for difference from control.

Conversion: SI to traditional units-NEFA: $1 \mathrm{mmol} / 1=1 \mathrm{mEq} / 1$.

final dose one hour before the test. Diet-treated subjects underwent a fourth episode of insulin-induced hypoglycaemia, when they took propranolol $80 \mathrm{mg}$ twice a day for 48 hours before the hypoglycaemia test. The drug sequence was randomised for each patient and all drugs were administered in identical-looking capsules to ensure a complete double-blind state.

The subjects fasted overnight, and at the beginning of the test they rested on couches. An indwelling intravenous cannula was inserted in each case and kept patent by irrigation with physiological saline. After a 15-minute equilibration period fasting blood samples were taken, the basal pulse rate was noted, and an intravenous bolus of Actrapid MC insulin was given. The dose of insulin was calculated according to body weight and overall diabetic control $(0 \cdot 2-0 \cdot 35 \mathrm{U} / \mathrm{kg})$. In some subjects a further dose of intravenous insulin was given at 30 minutes to ensure adequate hypoglycaemia. The insulin regimen for a given subject was then used in all his or her subsequent tests.

Further blood samples were taken at 30,60,90,120, and 150 minutes. The pulse rates were recorded and symptoms (palpitations, sweating, dizziness) were assessed on a five-point scale. If the blood glucose did not fall below $3 \mathrm{mmol} / \mathrm{l}(54 \mathrm{mg} / 100 \mathrm{ml})$ or hypoglycaemic symptoms did not occur the test series in that subject was repeated with a higher dose of insulin.

After the 150-minute sample all subjects performed a standardised exercise test equal to walking at $1.5 \mathrm{~km} /$ hour for three minutes. The pulse rates were noted before and after exercise.

The blood glucose concentrations were estimated using the GODPerid method and the blood lactate concentrations with a lactate dehydrogenase method (Boehringer packs). The blood non-esterified fatty acid concentrations were estimated using a modified Dole titremeteric assay. ${ }^{7}$ Paired Student's $t$ test was used for statistical analysis.

\section{Results}

Pulse rates, exercise tachycardia, and symptoms-Atenolol and propranolol reduced the resting pulse rates, and all drugs partly suppressed exercise-induced tachycardia, which indicated effective beta-adrenoreceptor blockade. In contrast to placebo, atenolol and acebutolol produced no increase of pulse rate during the tests and propranolol caused a sinus bradycardia (table I). Throughout the hypoglycaemia subjects taking atenolol had lower pulse rates than those taking acebutolol. Palpitation, sweating, and dizziness were not significantly affected by the drugs, although, as expected from the abolition of tachycardia, palpitation during hypoglycaemia was less prominent.

Blood glucose concentrations-The fasting blood glucose concentrations were higher in patients treated with hypoglycaemic drugs than in the diet-treated subjects (see figure). None of the betablockers produced any significant lowering of fasting blood glucose levels. Maximum hypoglycaemia occurred at 60 minutes in both groups and was equal to a mean fall in blood glucose of $69 \%$ in the diet-treated subjects and $75 \%$ in the drug-treated subjects (expressed as a percentage of the fasting blood glucose concentration). Neither atenolol or acebutolol potentiated the hypoglycaemic effect of insulin in diet-treated subjects, but propranolol significantly reduced the incremental area of the recovery curve. Acebutolol potentiated the hypoglycaemic effect of insulin in tablet-treated subjects, with a fall in mean blood glucose concentrations of $81 \%$ at 60 minutes $(P<0.01)$ and the concentration was also significantly lower than the control value at 90 and 150 minutes. Nevertheless, the incremental area of the blood glucose recovery curve was identical to that for placebo and atenolol. The mean blood glucose recovery curve on atenolol was similar to that for placebo in both groups of patients. 
Blood lactate concentrations-The mean fasting blood lactatc concentrations were higher in patients taking hypoglycaemic tablets (table II). None of the drugs produced any significant fall in fasting blood lactate concentrations. During hypoglycaemia the control mean blood lactate concentration rose by $76^{\circ}{ }^{\circ}$ at 90 minutes in diet-treated subjects and by $67^{\circ}$, in tablet-treated subjects. Acebutolol impaired this blood lactate response in tablet-treated subjects $(P<0.05)$ with a rise of only $33^{\circ}$ "at 90 minutes. Propranolol slightly reduced the inc:-emental area of blood lactate response in diet-treated subjects $(\mathrm{P}<0 \cdot 05)$. Atenolol had no significant effects on blood lactate concentrations in either group.

Blood NEFA concentrations-All drugs significantly lowered fasting blood NEFA concentrations in diet-treated subjects, and acebutolol also lowered them in drug-treated subjects (table III). After intravenous insulin administration the blood NEFA concentrations fell in all groups. The placebo blood NEFA concentration fell by $56^{\circ}{ }_{\text {, }}$ at 30 minutes in drug-treated subjects, and by $52^{\circ}{ }_{\circ}$ at 30 minutes in diettreated subjects. The secondary rise of blood NEFA concentrations from adrenaline-mediated lipolysis was reduced in acebutolol- and propranolol-treated diet-controlled subjects. No significant effects on blood NEFA concentrations were observed in the tablet-treated subjects

\section{Discussion}

The results show that these beta-adrenoreceptor blocking drugs differ in their effects on the metabolic responses during insulin-induced hypoglycaemia, and this probably reflects differences in pharmacological selectivity and ancillary properties. Propranolol delayed glucose recovery, as it does in normal subjects. Acebutolol potentiated the hypoglycaemic action of insulin in drug-treated diabetics in a manner similar to that found in normal subjects." Throughout the recovery phase the mean blood glucose concentration remained on average $0.7 \mathrm{mmol} / 1(12.6 \mathrm{mg} / 100 \mathrm{ml})$ lower when patients were taking acebutolol than when they were taking placebo, the incremental area being identical with that for control and atenolol curves. This implies that the magnitude of the adrenaline-induced glycogenolytic response was unaffected but that acebutolol impaired hepatic glucose output in some other way.

The beta-adrenoreceptors of the liver and skeletal muscle are thought to be predominantly of the beta $a_{2}$ type. Hence the beta ${ }_{2}$ adrenoreceptor blockade of the non-selective drugs might be expected to antagonise adrenaline-mediated glycogenolysis whereas the beta ${ }_{1}$-blocking drugs should have no such effect. Hepatic glycogenolysis may, however, also be stimulated directly by a low blood glucose concentration. Studies on liver preparations and exercising normal subjects have shown that drugs with a membrane-stabilising action inhibit glucose release from the liver in response to a low blood glucose concentration. ${ }^{x}$ Thus propranolol, possessing this action, impaired postexercise recovery of the blood glucose, whereas metoprolol, without membrane-stabilising activity had no such effect. Acebutolol also possesses membrane-stabilising activity, which probably accounts for its effect on the blood glucose concentration during induction of hypoglycaemia. Furthermore, it is not entirely devoid of beta ${ }_{2}$-blocking activity and this may also contribute to the hypoglycaemic effect. In contrast, atenolol, being beta specific and devoid of a membrane-stabilising action, does not affect the metabolic responses to insulin-induced hypoglycaemia.

These findings therefore support the hypothesis that betaadrenoreceptor blocking drugs which are highly beta ${ }_{1}$ specific and devoid of membrane-stabilising activity should be safer than non-selective drugs when used in diabetic patients at risk of hypoglycaemia.

We thank Jill Unsworth for her technical help; the staff of the biochemistry department, Pilgrim Hospital; and Imperial Chemical Industries Limited and May and Baker Limited for providing drugs.

\section{References}

${ }^{1}$ Kotler, M N, Berman, L, and Rubenstein, A H, Lancet, 1966, 2, 1389.

2 Abramson, E A, Arky, R A, and Woeber, K A, Lancet, 1966, 2, 1386.

${ }^{3}$ Davidson, N M, et al, Scottish Medical fournal, 1976, 22, 69.

${ }^{4}$ Deacon, S P, and Barnett, D, British Medical fournal, 1976, 2, 272.

${ }^{5}$ Newman, R J, British Medical fournal, 1976, 2, 447.

${ }^{6}$ Lancet, 1977, 1, 843.

7 Trout, D L, Fournal of Lipid Research, 1960, 1, 199.

${ }^{8}$ Pogatsa, G, Kaldor, A, and Vizi, E S, Drug Research, 1973, 23, 1085.

${ }^{9}$ Linton, S P, Scott, P H, and Kendall, M J, British Medical fournal, 1976, 2, 877.

(Accepted 6 September 1977)

\title{
Photochemotherapy in mycosis fungoides
}

\author{
L HODGE, D VELLA BRIFFA, A P WARIN, R W GANGE, S BLEEHEN
}

British Medical fournal, 1977, 2, 1257-1259

\section{Summary}

Six patients with mycosis fungoides were treated with methoxsalen and long-wave ultraviolet light. They were assessed clinically and histologically before and after treatment. All six patients showed clinical improvement.

St John's Hospital for Diseases of the Skin, London WC2H 7BJ

L HODGE, MRACP, research associate

D VELLA BRIFFA, MD, research associate

A P WARIN, MRCP, consultant dermatologist

$R$ W GANGE, MRCP, senior registrar

Hallamshire Hospital, Sheffield

S BLEEHEN, MRCP, consultant dermatologist
Histological clearing of both epidermis and dermis occurred in three patients, and epidermal clearing alone occurred in two.

Photochemotherapy may have a place in the treatment of the early and intermediate stages of mycosis fungoides, and it may also be useful as an adjunct to other forms of treatment in the more advanced stages.

\section{Introduction}

Mycosis fungoides is a malignancy of $T$ lymphocytes that predominantly affects the skin. Visceral involvement is not commonly recognised even in later stages, and many patients die of their disease without evidence of systemic disease.

Gilchrest et $a l^{1}$ reported the efficacy of photochemotherapy with systemic psoralens and long-wave ultraviolet A light (PUVA) in nine patients with mycosis fungoides but confirmed this histologically in only one. Hjortshoj and Schmidt ${ }^{2}$ reported 